\title{
Use of medications amongst older persons in Kaunas, Lithuania
}

\author{
Aurima Stankuniené ${ }^{1 *}$, Mindaugas Stankunas 2,3 , Mark Avery ${ }^{3}$, \\ Raimondas Radziunas ${ }^{1}$, Joaquim F.J. Soares ${ }^{4}$, M. Gabriella Melchiorre ${ }^{5}$, \\ Francisco Torres-Gonzalez ${ }^{6}$, Algirdas Baranauskas ${ }^{1}$ Jutta Lindert \\ 1 Department of Pharmaceutical Technology and Social Pharmacy, Lithuanian University \\ of Health Sciences, A. Mickeviciaus 9, LT-44307 Kaunas, Lithuania \\ 2 Department of Health Management, Lithuanian University of Health Sciences, \\ A. Mickeviciaus 9, LT-44307 Kaunas, Lithuania \\ 3 School of Medicine, Griffith University, Gold Coast, Queensland 4222, Australia \\ 4 Institution for Health Sciences, Department of Public Health Science, Mid Sweden University, \\ Holmgatan 10, Humlegården, Hus M, 851 70, Sundsvall, Sweden \\ 5 Scientific Technological Area, Socio Economic Research Centre, Italian National Institute of Health \\ and Science on Aging (INRCA), Via Santa Margherita 5, Ancona 60124, Italy \\ 6 Centro de Investigación Biomedica en Red de Salud Mental" CIBERSAM-Granada University, \\ Av Madrid, 11 PC:18071 Granada, Spain \\ 7 Department of Public Health, Protestant University of Applied Sciences, \\ Paulusweg 6, 71638 Ludwigsburg, Germany and Department of Psychology and Sociology, \\ University of Leipzig, Leipzig, Germany
}

Received 28 March 2013; Accepted 5 August 2013

\begin{abstract}
Aim: To evaluate the associations between socio-economical factors and the use of medications in the elderly. Methods: The data was collected in a cross-sectional study in 2009. We received 624 completed questionnaires (response rate $-48.9 \%$ ) from elderly people aged 60-84 years living in Kaunas (Lithuania). For an evaluation of the impact of explanatory variables on the analyzed events (binary dependent variable), an Enter model of logistic regression was used. Results: Our findings suggest that $50.8 \%(n=317)$ of respondents used at least one drug daily. $18.3 \%(n=114)$ of respondents indicated that they use medications regularly, but not on a day-by-day basis. One quarter $(25.6 \% ; n=160)$ used medication only on an "at need" basis. Only $5.3 \%(n=33)$ of older persons did not use any medications at all. Logistic regression showed that being male $(\mathrm{OR}=0.67 ; 95 \% \mathrm{Cl}: 0.45-0.98)$ was associated with using medications "regularly + daily." For the use of "daily" medications, older age $(\mathrm{OR}=1.33$; $95 \% \mathrm{Cl}: 1.15-1.53)$ was associated with using medications daily. An opposite association was observed for respondents having no paid work ( $\mathrm{OR}=0.48$; $95 \% \mathrm{Cl}: 0.26-0.82)$. Conclusions: Our study suggests that more than half of older persons in Lithuania use medications every day. Use was associated with socioeconomic factors (gender, age, and employment status).
\end{abstract}

Keywords: Older persons • Medication use • Lithuania $•$ ABUEL

(C) Versita Sp. z 0.0. 


\section{Background}

The last two decades has brought many challenges for Lithuanian society. Lithuania entered a new era in this time with many opportunities for radical improvements. Nevertheless, the population of the country has been exposed to a new and unfamiliar social environment and consequently has experienced tremendous stress [1]. The consequences of this stress include a decreasing number of births, high mortality rates, emigration etc. [2]. These and other factors caused Lithuania to experience one of the fastest aging demographic profiles in the European Union (EU). In relation to the future, it is argued that by the year 2060 the old-age dependency ratio will be $56.65 \%$ and it will be one of the highest in the EU [3]. The healthy life expectancy, at age 65, is one of the shortest in the EU (6.7 years for females and 6.1 years for males with the EU average at 8.6 years for both sexes) [4]. A recent multinational study revealed that older persons in Lithuania have identified more somatic complaints than counterparts in Sweden, Greece, Spain, Italy or Germany [5]. This argues that health situations for older people in Lithuania are of concern. Such intensive demographic ageing and poor health status of older persons will pose challenges for the use of health care services [6]. Studies from all around the world argue that elderly people are the main users of health care services and consume disproportionately for all prescribed drugs $[7,8]$. Many older people are taking more than four or five different medications. There is also the problem of inappropriate use of pharmaceutical drugs, a factor that can also result in hospitalizations [9-13]. The use of medications in the elderly is a health care and public health issue that is highlighted in the international scientific literature [14].

In spite of growing concern, only very few studies have been carried out in this field in Lithuania [15-17]. These studies have analyzed medication non-compliance amongst the elderly in Lithuania [15] relating to: accessibility to medications (based on the respondent's self-reported experience of financial problems in obtaining necessary medicaments) [16] and refrain from buying prescribed medications [17]. However, very little is known about the use of pharmaceutical products in the elderly and their associations with some socio-economic factors. Some authors highlight that high costs for prescription medications could lead to middle-aged and elderly people with chronic illnesses restricting their use of these medications and this in turn can lead to poorer health outcomes [18].

The aim of this study was to assess the use of medications amongst elderly people in Kaunas (Lithuania) and their associations with selected socio-economic factors.

\section{Methods}

Data for this study was collected during the European project "Elder abuse: a multinational prevalence study - ABUEL" [5]. The study was carried out in seven urban communities across Europe: in Stuttgart (Germany), Athens (Greece), Ancona (Italy), Kaunas (Lithuania), Porto (Portugal), Granada (Spain) and Stockholm (Sweden). This paper refers to the results from the Kaunas population sample.

Participants in this study consisted of randomly selected women and men from the general population living in Kaunas, the second largest city located in the central part of Lithuania. The population of the city is 321,000 (estimated 2011). The sample size of the study population was calculated based on expected ranges of prevalence of violence as observed in previous surveys. Assuming a prevalence of abuse of $13 \%$ [19] with a precision of $2.6 \%$, a sample size of 633 individuals was required. The sample was calculated proportional to age-gender groups in the population in Kaunas. The Residents' Register Service, maintained by the Ministry of the Interior, provided the study sample of 1,276 people. Inclusion criteria were for people who: 1) were age 60-84 years; 2) did not suffer from dementia or other cognitive impairments; 3 ) had a legal residential status (national citizens or documented migrants); 4) lived in the community or in sheltered houses; 5) could read and write in Lithuanian; and 6) agreed to participate in the study. Recruitment of eligible participants and data collection was performed during April to July, 2009. Data was collected through face-to-face interviews, carried out by trained interviewers. Completed questionnaires were returned to the research team and data was aggregated for analysis. The total number of returned survey questionnaires was 624 (response rate $48.9 \%$ ). The investigated sample was representative of the elderly population in Kaunas (from 60 to 84 years) with regard to the main demographic characteristics (gender and age). More detailed description of sampling, data collection procedures, and study limitations are described in a separate paper [20].

The participants completed a standardized questionnaire with various scales and questions. Use of medications was measured following the respondents answers to the question about how often they used medications. They could choose one of the following answers: "No", "At need", "Regularly", or "Daily".

Data were computed, coded and analyzed using the Statistical Package for the Social Sciences for Windows (Version 11.0 (SPSS Inc.)). The following statistical analyses were applied: 1) descriptive statistics; and 2) logistic regression. 
Continuous variables were presented as a mean/ standard deviation $(\mathrm{M} \pm \mathrm{SD})$. For the evaluation of distribution, skewness and kurtosis were calculated. The correlation between two variables was assessed using the Chi-square test $\left(\mathrm{X}^{2}\right)$ for categorical variables. For evaluation of the impact of the explanatory variables on the analyzed event, (binary dependent variable), an Enter model of logistic regression was used. The dependent variable was the use of any medication. The independent variables were sex, age, education, habitation status, present employment status, worrying about daily expenses. Associations were measured using odds ratio (OR) and calculating the $95 \%$ confidence interval $(\mathrm{Cl})$. Differences in results at the $p<0.05$ level were considered statistically significant. The Lithuanian State Data Protection Inspectorate and the Kaunas Regional Bioethics Committee granted permission to perform this study.

\section{Results}

Of the 624 respondents $35.4 \%(n=221)$ were male and $64.6 \%(n=403)$ female. The distribution of respondents by age was the following: 60-64 years $144(23.1 \%)$, 65-69 years $147(23.6 \%), 70-74$ years $144(23.1 \%)$, 75-79 years $120(19.2 \%)$ and $80-84$ years $(11.1 \%)$. The mean age of participants was $70.5 \pm 6.64$ years (kurtosis $-0,993$; skewness 0,179$)$. A significant proportion of the respondents $(45.2 \%)$ had secondary education. Twenty-six per cent had tertiary education and $28.8 \%$ primary, or less than primary, education. Worries about daily expenses were reported by $72.9 \%$ of the respondents $(13.9 \%$ were always worried; $21.5 \%$ often worried; $37.5 \%$ quite often worried). Only $27.1 \%$ reported no worries about daily expenses.

Our findings suggest that more than half $(50.8 \%)$ of respondents used at least one drug daily. $18.3 \%$ responded that they use medications regularly but not on a day-by-day basis. One quarter (25.6\%) used medication only on an "at need" basis. Meanwhile only $5.3 \%$ of elders did not use medications at all. The distribution of use of medications by different socio-economic groups is presented in Table 1.

Table 1. Prevalence of medication use in different socio-economic groups.

\begin{tabular}{|c|c|c|c|c|c|}
\hline \multirow{2}{*}{ Variables } & \multicolumn{4}{|c|}{$\% / n$} & \multirow{2}{*}{$x^{2} ; d f ; p$} \\
\hline & No & At need & Regularly & Daily & \\
\hline Total & $5.3 / 33$ & $25.6 / 160$ & $18.3 / 114$ & $50.8 / 317$ & \\
\hline \multicolumn{6}{|l|}{ Sex } \\
\hline Males $(n=221)$ & $6.3 / 14$ & $29.9 / 66$ & $16.7 / 37$ & $47.1 / 104$ & \multirow{2}{*}{$\begin{array}{c}x^{2}=4.47 \\
d f=3 \\
p=0.215\end{array}$} \\
\hline Females $(n=403)$ & $4.7 / 19$ & $23.3 / 94$ & $19.1 / 77$ & $52.9 / 213$ & \\
\hline \multicolumn{6}{|l|}{ Age group } \\
\hline $60-64$ yr. $(n=144)$ & $5.6 / 8$ & $32.6 / 47$ & $28.5 / 41$ & $33.3 / 48$ & \multirow{5}{*}{$\begin{array}{c}\mathrm{X}^{2}=42.94 ; \mathrm{df}=12 \\
\mathrm{p}<0.001\end{array}$} \\
\hline $65-69$ yr. $(n=147)$ & $8.8 / 13$ & $27.2 / 40$ & $19.7 / 29$ & $44.2 / 65$ & \\
\hline $70-74$ yr. $(n=144)$ & $4.2 / 6$ & $20.1 / 29$ & $16.7 / 24$ & $59.0 / 85$ & \\
\hline $75-79$ yr. $(n=120)$ & $2.5 / 3$ & $24.2 / 29$ & $10.0 / 12$ & $63.3 / 76$ & \\
\hline $80-85$ yr. $(n=69)$ & $4.3 / 3$ & $21.7 / 15$ & $11.6 / 8$ & $62.3 / 43$ & \\
\hline \multicolumn{6}{|l|}{ Education } \\
\hline Less than primary $(n=34)$ & $11.8 / 4$ & $20.6 / 7$ & $32.4 / 11$ & $35.3 / 12$ & \multirow{4}{*}{$\begin{array}{c}x^{2}=22.18 ; d f=9 \\
p=0.008\end{array}$} \\
\hline Primary $(n=146)$ & $2.1 / 3$ & $22.6 / 33$ & $13.7 / 21$ & $61.6 / 90$ & \\
\hline Secondary $(n=282)$ & $5.0 / 14$ & $25.2 / 71$ & $17.7 / 50$ & $52.1 / 147$ & \\
\hline Tertiary $(n=138)$ & $5.1 / 7$ & $32.6 / 45$ & $20.3 / 28$ & 42.0 / 58 & \\
\hline \multicolumn{6}{|l|}{ Habitation } \\
\hline Married / cohabiting $(n=352)$ & $5.7 / 20$ & $25.3 / 89$ & $20.7 / 73$ & $48.3 / 170$ & \multirow{2}{*}{$x^{2}=3.97 ; d f=3 ; p=0.265$} \\
\hline Single / divorced / windowed $(n=272)$ & $4.8 / 13$ & $26.1 / 71$ & $15.1 / 41$ & $54.0 / 147$ & \\
\hline \multicolumn{6}{|l|}{ Still work paid work } \\
\hline Yes $(n=99)$ & $6.1 / 6$ & $35.4 / 35$ & $28.3 / 28$ & $30.3 / 30$ & \multirow{2}{*}{$\begin{array}{c}x^{2}=20.65 ; d f=3 \\
p<0.001\end{array}$} \\
\hline No $(n=525)$ & $5.1 / 27$ & $23.8 / 125$ & $16.4 / 86$ & $54.7 / 287$ & \\
\hline \multicolumn{6}{|l|}{ Worries about daily expenses } \\
\hline Never $(n=169)$ & $8.3 / 14$ & $21.9 / 37$ & $12.4 / 21$ & $57.4 / 97$ & \multirow{4}{*}{$\begin{array}{c}X^{2}=31.00 ; d f=9 \\
p<0.001\end{array}$} \\
\hline Quite often $(n=234)$ & $6.4 / 15$ & $28.6 / 67$ & $24.8 / 58$ & $40.2 / 94$ & \\
\hline Often $(n=134)$ & $3.0 / 4$ & $21.6 / 29$ & $17.2 / 23$ & $58.2 / 78$ & \\
\hline Always $(n=87)$ & $0 / 0$ & $31.0 / 27$ & $13.8 / 12$ & $55.2 / 48$ & \\
\hline
\end{tabular}

$\mathrm{x}^{2}$ - Chi -square test, $d f$ - degree of freedom; $p$ - significance level, $n$ - number of cases. 
Logistic regression was used to measure the association between socioeconomic factors and use of medications (Table 2). We evaluated "risk" associations for the use of medications on the basis of "regularly + daily" and only for "daily". Our findings suggest, that being male $(\mathrm{OR}=0.67)$ was associated with using medications "regularly + daily". For the use of medications "daily", older age (OR=1.33) increased the "risk" to use medications daily. The opposite effect was observed with those not employed $(\mathrm{OR}=0.48)$. Other factors have not shown any significant influence.

Table 2. Odds ratios for use of medications "regularly + daily" and "daily", logistic regression analysis.

\begin{tabular}{|c|c|c|c|}
\hline Factors & OR & $95 \% \mathrm{Cl}$ & $\mathrm{p}$ \\
\hline \multicolumn{4}{|l|}{ "Regularly + daily" use of medications (Dv) } \\
\hline Being male (Iv) & 0.67 & $0.45-0.98$ & 0.040 \\
\hline Age (each age group) (Iv) & 1.14 & $0.98-1.33$ & 0.084 \\
\hline Education (higher level of education) (IV) & 0.86 & $0.69-1.07$ & 0.182 \\
\hline Living not alone (Iv) & 0.69 & $0.47-1.03$ & 0.069 \\
\hline Is not employed (Iv) & 0.69 & $0.41-1.15$ & 0.157 \\
\hline $\begin{array}{l}\text { Daily worries about the expenses (each } \\
\text { group of more intensive worries) (Iv) }\end{array}$ & 1.06 & $0.89-1.27$ & 0.491 \\
\hline \multicolumn{4}{|l|}{ "Daily" use of medications (Dv) } \\
\hline Being male (Iv) & 0.86 & $0.60-1.24$ & 0.422 \\
\hline Age (each age group) (Iv) & 1.33 & $1.15-1.53$ & $<0.001$ \\
\hline Education (higher level of education) (Iv) & 0.96 & $0.78-1.18$ & 0.673 \\
\hline Living not alone (IV) & 0.85 & $0.59-1.24$ & 0.384 \\
\hline Is not employed (IV) & 0.48 & $0.26-0.82$ & 0.007 \\
\hline $\begin{array}{l}\text { Daily worries about the expenses (each } \\
\text { group of more intensive worries) (Iv) }\end{array}$ & 1.06 & $0.90-1.25$ & 0.498 \\
\hline
\end{tabular}

\section{Discussion}

Our results revealed that males were more likely to use less pharmaceuticals than females. Regularly and daily use of medications was reported by $72.0 \%$ of females and $63.8 \%$ of males. This is in line with other studies which report that females use medicines than males [21-23]. For instance, a study in USA has identified that women (aged 65 and over) spent about $\$ 1,178$ on drugs, about $17 \%$ more than the $\$ 1,009$ average expenditure by men [24]. One of explanation of this pattern, could be that women in general report more bodily distress (like menopause, osteoporosis) and more numerous, intense and frequent somatic symptoms than men [25]. This may cause females to purchase more pharmaceutical products [26] and spend a considerable amount of the household income on them. Other authors explain this gender pattern by arguing that women are central to the process of communication about health and therapies and they appear to draw on a richer repertoire of knowledge, perceptions and attitudes regarding medications [27]. Subsequently, that position leads to reporting higher overall use of medication than men do.

Findings from the study suggest that old age was associated with increased use of medications. These findings add to a growing number of studies which show that older people use more medications and health care services $[26,28]$. A recent study in Lithuania revealed old age (in the age group 60-84 years) was independently associated with a decreased risk of refraining from buying prescription medications [17]. Moreover, the same study has demonstrated that age was not significant for the identification of financial problems as the main reason of refraining from medication use. Studies have shown economic problems become a less important factor for refraining from buying drugs in older age people [29-31]. This association can be explained, based on findings, that that the chronic nature of health problems among older persons reduces the risk of refraining from buying the prescription medications [30]. The presence of chronic health problems (which are more expressed in older age) leads to the point that older people follow more precisely the physician's recommendations and buy prescription drugs [17,33-35].

It was measured that the absence of paid work decreased the risk to the use medications in 60-84 year elderly. This association could be explained by the fact that employment is a very important factor for material wellbeing and self reported health all over the world and as well in Lithuania and other post - soviet countries [36,37]. Lithuanian social support systems (especially for the elderly) are underdeveloped. The transition from paid work to pension causes significant changes in incomes. The average salary in Lithuania is 2,138 LTL/ month (or 619 EUR). Meanwhile the average aged pension is $815 \mathrm{LTL} /$ month (or 236 EUR) [38]. The argument here is that incomes decrease 2.6 times and this affects the possibility to purchase required medications. On the other hand the Lithuanian Sickness Fund provides $100 \%$ compensation of cost for buying most of the drugs used by the elderly [39].

Some possible study limitations are noteworthy. First, the results are possibly limited due the respondents' selection process. The participants (samples of women and men) were recruited from Kaunas which is the second largest city in Lithuania. Therefore, the results of this study do not represent the situation in rural areas. Secondly, non-responders were not investigated. It could be that those who refused to respond had different patterns in their use of medications. Thirdly, the accuracy of the data was dependent on the participants' subjective assessment of their situation. No objective evaluations (e.g. patient records) have been performed to corroborate their responses. 


\section{Conclusions}

More than half $(50.8 \%)$ of the people in the $60-84$ years age group have used medications daily. Another 18.3\% have used medication regularly but not every day. Analysis shows that being male and having no paid work was associated with decreased risk for intensive use of medications. Meanwhile, older age had an opposite association.

\section{References}

[1] Kaledien R., Sauliune S., Mortality of Lithuanian population over 2 decade of independence: critical points and contribution of major causes of death, Medicina (Kaunas), 2013, 49, 36-41

[2] Biermann U., Stiller S., Migration in the Baltic Sea region in the context of demographic change, $\mathrm{J}$. East-West Business, 2013, 19, 105-121

[3] Eurostat, Projected old-age dependency ratio, http:// epp.eurostat.ec.europa.eu/tgm/table.do?tab=table\& plugin=1\&language $=$ en $\&$ pcode $=$ tsdde 511

[4] Eurostat, Healthy life years and life expectancy at age 65 , by sex, http://epp.eurostat.ec.europa.eu/ tgm/refreshTableAction.do?tab=table\&plugin $=1 \& p c$ ode=tsdph220\&language $=$ en

[5] Soares J.J., Barros H., Torres-Gonzales F., IoannidiKapolou E., Lamura J., Lindert J. et al., Abuse and Health Among Elderly in Europe, Kaunas, Lithuanian University of Health Sciences Press, 2010

[6] Kanopiene V., Mikulioniene S., Population ageing and its challenges to health care system, Gerontologija, 2000, 7, 188-200

[7] Department of Statistics of Lithuania, Number of medications users, Vilnius, 2005, http://db1.stat.gov.lt

[8] Office of Health Economics, Compendium of Health Statistics (9th Eds), London, 1995

[9] Rechel B., Doyle Y., Grundy E., McKee M., How can health systems respond to population ageing?, Copenhagen, World Health Organization, on behalf of the European Observatory on Health Systems and Policies, 2009

[10] Oxley H., Policies for healthy ageing: an overview, Paris, OECD, 2009

[11] Ritsatakis A (Eds.), Demystifying the myths of ageing, Copenhagen, WHO Regional Office for Europe, 2008

[12] Curtis L.H., Ostbye T., Sendersky V., Hutchison S., Dans P.E., Wright A., et al., Inappropriate prescribing for elderly Americans in a large outpatient population, Arch. Intern. Med., 2004, 164, 1621-1625

\section{Acknowledgments}

We would like to express our appreciation for the financial support by the European Union through the EAHC, which made possible the realization of the project. We extend also our appreciation to the staff of EAHC, and in particular Dr. Guy Dargent, for their help. We would like to express our appreciation to all participating institutions and to the staff involved in ABUEL. Finally, and most of all, all authors appreciate the kindness, efforts and answers of the elderly people who participated in ABUEL.

[13] Dimitrow M.S., Airaksinen M.S., Kivela S.L., Lyles A., Leikola S.N., Comparison of prescribing criteria to evaluate the appropriateness of drug treatment in individuals aged 65 and older: A systematic review, J. Am. Geriatr. Soc., 2011, 59, 1521-1530

[14] Molony S.L., Monitoring medication use in older adults, Am. J. Nurs., 2009, 109, 68-78

[15] Antanaviciene J., Management of drug use in older patients. MPH thesis, Lithuanian University of Health Sciences, Department of Health Management, 2010

[16] Plieskis M., The accessibility of the primary health care and the citizens satisfaction with the services in the context of the development of family medicine, PhD dissertation, Lithuanian University of Health Sciences, Department of Health Management, 2005

[17] Stankuniene A., Radziunas R., Stankunas M., Soares J.F., Baranauskas A., Ioannidi-Kapolou E. et al., Causes of refrain from buying prescribed medications among the elderly in Kaunas, Lithuania, Medicina (Kaunas), 2011, 47, 291-296

[18] Heisler M., Langa K.M., Eby E.L., Fendrick M., Kabeto M.U., Piette J.D., The health effects of restricting prescription medication use because of cost, Medical Care, 2004, 42, 626-634

[19] Cooper C.A., Selwood A., Livingston G., The prevalence of elder abuse and neglect. A systematic review, Age Ageing, 2008, 37, 151-160

[20] Lindert J., Luna J., Torres-Gonzalez F., Barros H., Ioannidi-Kapolou E., Quattrini S. at al., Study design, sampling and assessment methods of the European study "Abuse of the Elderly in the European Region”, Eur. J. Public Health, 2012, 22, 662-666

[21] Jyrkka J., Enlund H., Korhonen M.J., Sulkava R., Hartikainen S., Patterns of drug use and factors associated with polypharmacy and excessive polypharmacy in elderly persons: results of the Kuopio 75+ study: a cross-sectional analysis, Drugs Aging, 
2009, 26, 493-503

[22] Chen Y.F., Dewey M.E., Avery A.J., Analysis Group of The MRCCFA Study, The Medical Research Council Cognitive Function and Ageing Study (MRC CFAS) Self-reported medication use for older people in England and Wales, J. Clin. Pharm. Ther. 2001, 26, 129-140

[23] Special Eurobarometer 345, Mental Health, 2010, http://ec.europa.eu/health/mental_health/docs/ ebs_345_en.pdf

[24] Correa-de-Araujo R., Miller G.E., Banthin J.S., et al., Gender differences in drug use and expenditures in a privately insured population of older adults, J. Womens Health, 2005, 14, 73-81

[25] Stankunas M., Soares J.F.J., Stankuniene A., Melchiorre M.G, Torres-Gonzales F., loannidiKapolou E., et al. Differences in reporting somatic complaints in elderly by education level, Cent. Eur. J. Med., 2013, 8, 125-131

[26] Linjakumpu T., Hartikainen S., Klaukka T., Veijola J., Kivela S.L., Isoaho R., Use of medications and polypharmacy are increasing among the elderly, J. Clin. Epidemiol., 2002, 55, 809-817

[27] Obermeyer C.M., Schulein M., Hardon A., Sievert L.L., Price K., Santiago A.C., et al., Gender and medication use: an exploratory, multi-site study, Women Health, 2004, 39, 57-73

[28] World Health Organization, Health21: The health for all policy framework for the WHO European Region, Copenhagen, 1999

[29] Piette J.D., Hiesler M., Wagner T.H., Problems paying out-of-pocket medication costs among older adults with diabetes, Diabetes Care, 2004, 27, 384-391

[30] Kemp A., Roughead E., Preen D., Glover J., Semmens J., Determinants of self-reported medicine underuse due to cost: a comparison of seven countries, J. Health Serv. Res. Policy, 2010, 15, 106-114

[31] Kennedy J., Christopher E., Prescription noncompliance due to costs among adults with disabilities in the United States, Am. J. Public Health, 2002, 92, 1120-1124

[32] Carrie A., Impact of residence on prevalence and intensity of prescription drug use among older adults, Ann. Pharmacoter., 2006, 40, 1932-1938

[33] Murrell S.A., Meeks S., Psychological, economic, and social mediators of the education-health relationship in older adults, J. Aging Health, 2002, 14, 527-550

[34] Avlund K., Davidsen M., Schroll M., Changes in functional ability from ages 70 to 75 , J. Aging Health, 1995, 7, 254-282

[35] Morgan M., Marital status, health, illness, and service use, Soc. Sci. Med., 1980, 14A, 633-643

[36] Bobak M., Pikhart H., Rose R., Hertzman C., Marmot M., Socioeconomic factors, material inequalities, and perceived control in self-rated health: cross-sectional data from seven post-communist countries, Soc. Sci. Med., 2000, 51, 1343-1350

[37] Stankunas M., Kalediene R., Starkuviene S., Sense of coherence and its associations with psychosocial health: results of survey of the unemployed in Kaunas, Medicina (Kaunas), 2009, 45, 807-813

[38] State Social Insurance Fund Board under the Ministry of Social Security and Labour of Republic of Lithuania, Main social factors, http://www.sodra. It/index.php?cid=284

[39] National Health Insurance Fund under the Ministry of Health of Republic of Lithuania, Information about the PSDF budget expenses for compensation of costs for buying medical equipment, http:// www.vlk.lt/vlk/pag/files/kv/2009m_kv_islaidos.pdf 